\title{
EL LIBRO Y LA LECTURA EN VALENCIA (1300-1410). NOTAS PARA SU ESTUDIO
}

La imagen que en la actualidad tenemos del libro bajomedieval, de su utilización y difusión, carece aún de nitidez, probablemente debido a que entre los numerosos estudios que sobre él se han realizado, muy pocos han tratado de ofrecer una visión global del fenómeno '. Nuestro panorama historiográfico incluye muchos y diversos análisis sobre aspectos puntuales de la cuestión, así como otros trabajos destinados a la publicación de documentos aislados, frecuentemente, inventarios de bibliotecas de cierta relevancia. Fue esta dispersión de la labor investigadora relativa al libro una de las razones que nos decidió a intentar llevar a cabo un estudio de conjunto sobre el libro, su difusión y uso en la sociedad de la Baja Edad Media, en el que el interés no recayera sobre las grandes bibliotecas, sino en las pequeñas colecciones privadas que no han dejado huella, en el que las lecturas de los intelectuales reconocidos no eclipsaran a las practicadas por los individuos anónimos.

La ciudad de Valencia ofrecía un terreno adecuado para la materalización de un estudio de estas características. La ciudad constituye un espacio comunicativo audiovisual, un espacio definido por la imagen y la palabra ${ }^{2}$. En los medios urbanos bajomedievales la comunicación se desarrollaba a través de diversos canales, que, a su vez, remitían a distintos niveles de comunicación: oral, visual, escrito. Al individuo socialmente activo, a su clase social, le corresponde hacerse conocer en el seno de su comunidad; asimismo, debe conocer a los demás grupos que la integran. Sin embargo, la participación en cada uno de ellos por parte de cada individuo o grupo social, así como la forma en que se produce dicha participación -activa o pasiva-, se halla condicionada por las posibilidades de que hayan disfrutado de acceder a cada uno de esos canales. El estudio del libro en el medio urbano es, por tanto, el

' Nos referimos a la problemática de libro en la España bajomedieval, sobre la que, desgraciadamente, no se ha insistido en demasía. En este artículo tratamos de exponer algunos resultados de una investigación realizada sobre el libro y su lectura en Valencia a lo largo del siglo XIC, así como de llamar la atención sobre esta parcela de la investigación, descuidada en cuanto a estudios de conjunto se refiere.

2 En la actualidad, el profesor Francisco Gimeno BLAY un trabajo sobre el tema Los signos escritos de la ciudad, en el que se ocupa en profundidad de esta cuestión. 
estudio de una manifestación de uno de sus vehículos comunicativos, la escritura.

Contábamos, en el origen de este proyecto, con un término ad quem, el libro de Philippe Berger Libro y lectura en la Valencia del Renacimiento ${ }^{3}$, cuyo punto de partida se sitúa en el momento en que se produjo la introducción de la imprenta. De otro lado, disponíamos de publicaciones que, por sus características se convertirían en importante referencia para nuestro trabajo, sobre todo en términos de comparación, ya que trataban sobre el libro y la lectura en diversos estados de la Corona de Aragón: El llibre català a la casa mallorquina, de Llompart, Manuscrits en català anteriors a la imprenta, de Madurell, Livre et société en Sicile, de Henri Bresc ${ }^{4}$. Todos ellos, asimismo, se desarrollaban en un tiempo largo'. La acotación cronológica constituía, de hecho, una cuestión delicada. A lo largo de los siglos XIV y XV se produjeron una serie de mutaciones fundamentales en lo que a la Cultura Escrita se refiere: el retroceso de la memoria personal en beneficio del archivo, la aparición de la noción explícita de Historia, la gramaticalización de la lengua vulgar, la disociación de un código oral y un código escrito... modificaron progresivamente las relaciones de los individuos con el escrito y en concreto con el libro. El siglo XIV marca el inicio de un proceso que continuará en los siglos siguientes. Deseábamos conocer cuáles eran las condiciones del libro y la lectura en el momento en que se originó dicho proceso, para detectar las modificaciones que se introducirían en el panorama librario, así como las resistencias que éste ofrece a los cambios. Elegimos así el Trescientos como testimonio de una actitud ante libro y lectura que se definía por una concepción instrumental de ambos, que evolucionó bajo la presión de los cambios que se operaban en la sociedad contemporánea, -que eran tanto de naturaleza social, como cultural o religiosa- y de las actitudes sociales y mentales que de ellos se derivan.

Definidas las coordenadas espacio-temporales, era necesario proceder a la selección de las fuentes. De un lado, contábamos con los materiales tradicionalmente utilizados para el estudio del libro en las sociedades del pasado, los protocolos notariales, de los que los archivos de la ciudad de Valencia cuentan con una buena muestra ${ }^{6}$. Junto a ellos disponíamos asimismo de las fuentes

3 P. BeRger, Libro y lectura en la Valencia del Renacimiento, Valencia, 1987.

4 H. BRESC, Liure et société en Sicile (1929-1499), Palermo, 1971; G. LLOMPART, El llibre català a la casa mallorquina (1350-1550), «Analecta Sacra Tarraconesian, 48 (1975) pp. 193-240 y 49-50 (1976-1977) pp. 57-114; J. MADURELL, Manuscrits en català anteriors a la imprenta (1321-1474). Contribució al seu estudi, Barcelona, 1974.

s Cfr. J. LE GOFF, Tiempos breves, tiempos largos, en IDEM, Lo maravilloso y lo cotidiano en el Occidente medieval, Barcelona, 1985.

- En la ciudad de Valencia se conservan alrededor de cuatrocientos protocolos notariales del siglo XIV, distribuidos entre el Archivo del Reino de Valencia, Archivo Municipal, Archivo de la Catedral y ante libro y lectura que se definía por una concepción instrumental Archivo del Colegio de Corpus Cbristi. 
directas, los manuscritos y los testimonios de su utilización -correcciones, notas de lectura...-, así como las fuentes iconográficas, literarias... etc.

Al decantarnos por una fuente indirecta como la notarial, restringíamos conscientemente el ámbito de nuestra investigación. Ahora bien, considerábamos necesaria la tarea de efectuar una revisión sistemática de las fuentes y extraer toda la documentación relativa al libro y a sus formas de utilización con el fin de sentar las bases de un proyecto global a realizar en diversas etapas.

Mucho se ha escrito acerca de las dificultades que entraña la búsqueda de la documentación concerniente al libro en los protocolos notariales y no repetiremos lo que ya se ha dicho'. Nos limitaremos a señalar que la información extraída es sumamente irregular -tanto en su contenido como en su secuencia temporal- lo que no permite la cuantificación de los datos obtenidos, a pesar de que algunos autores que se han ocupado de la problemática del libro bajomedieval a partir de materiales similares no han renunciado a ella ${ }^{3}$. No se trata sólo de la dificultad que conlleva lo fragmentario de la información, sino de la falta de representatividad de los resultados: En 1985 Attilio BartoliLangeli puso de relieve cómo para las épocas preestadísticas el Alfabetismo es un objeto incognoscible, porque la fragmentariedad de las fuentes disponibles no permite la cuantificación ni, en consecuencia, la serialización, y en caso de que fueran factibles, no son válidas como sistemas para recuperar el conjunto anónimo del ente social ni para la medición de su capacidad alfabética ${ }^{\text {. }}$

Al abordar el estudio del libro y sus formas de utilización, la lectura fundamentalmente, tratábamos de hacerlo desde una perspectiva global, como testimonio escrito indisociable del medio sociocultural en que fue producido y utilizado. El objetivo no lo constituía el libro como un indicador cultural, sino como producto escrito resultante del funcionamiento de una sociedad, de sus necesidades de comunicación. Era necesario, consecuentemente, el análisis de la difusión social del libro, como objeto material y producto cultural, y de la lectura como la principal de sus formas de utilización y de la función que le era atribuída en el medio que lo producía y se servía de él.

' Entre otros, B. BenASSAR, Los inventarios 'post morten' y la bistoria de las mentalidades. Actas del II Coloquio de Metodología Histórica Aplicada, Santiago de Compostela, 1984, pp. 134-146; G. LANARCA LANGA, Las bibliotecas privadas en Ins protocolos motariales. Valencia (1740-1808), «Anates de la Universidad de Alicante. Revista de Historia Moderna, 4. Libros, libreros y lectoresn (1984), pp. 189-209; M. CHEVALIER, Lectura y lectores en la España del siglo XVI y XVI; Medrid, 1976, pp. 41 y ss.

- Es el caso, por ejemplo, de Philippe Berger o de Christian Bec, quien así lo expone tanto en Les Marcbands óntiuains. Affoines et Humanisme à Florence (1375-1434), Parfs, 1967, como en Les livres des farvinitiss (1413-1608), Firenze, 1984.

9 Vid. A. BARTOLI LANGELI, Storia dell' alfabetismo e metodo quantitativo. III Curso de Estudios Universitarios Benasal-Casrellón. Paleografia (junio, 1985). 
La escritura es uno de los vehículos de los que una sociedad se ha dotado para satisfacer sus necesidades comunicativas, fruto de su funcionamiento y evolución. Albert d'Haenens define la relación escrituraria como una variante visual de la relación informativa ${ }^{10}$. La relación informativa es ejercida por el hombre a través de los medios de que dispone -los sentidos, que funcionan como vias de acceso- y por aquéllos de los que se dota -los medios de comunicación, que funcionan como soportes-. La escritura es uno de esos soportes, un útil de la relación informativa a la que transforma en relación escrituraria ". La escritura, a diferencia del lenguaje, no es un fenómeno eterno en la historia, sino que, contrariamente, la presencia de sistemas de fijación escrita del pensamiento y del lenguaje y el recurso a ellos, se hallan limitados tanto en el tiempo como en su difusión social ${ }^{2}$. De otro lado, la escritura en cuanto vehículo de comunicación no mantiene una relación unívoca con los integrantes del medio social que se sirve de ella, ya que no todos participan de este vehículo, ni quienes participan lo hacen en la misma medida ${ }^{13}$. Por ello, no podemos preguntarnos por la función del libro o de otro testimonio escrito, sino por las funciones que cada sociedad o medio sociocultural atribuía a su producción escrita ${ }^{14}$.

Una visión global del libro comporta necesariamente el análisis de todos los aspectos tocantes a él, de los caracteres materiales de los manuscritos, de los usos de que eran objeto, de las tipologías librarias resultantes de la conjunción de ambos. El estudio de la utilización que se hacía de los libros, ésto es, de su funcionalidad, nos remite de un lado, al análisis de las formas de su transmisón en el tiempo y de su acumulación en el espacio -la formación de las bibliotecasy de otro nos conduce a las diversas modalidades de lectura que eran puestas en práctica, la composición social, cultural y profesional del público lector y el grado de identificación de éste con el conjunto de los individuos poseedores de manuscritos, la relación entre la presencia del libro en un medio y la capacidad y práctica de la lectura en dicho medio. Nuestra pretensión, en última instancia, era reconstruir la actitud que hacia el libro se mantenía, individual y colectivamente, actitud que era consecuencia de la concepción que el individuo de la época tenía de la cultura escrita.

Nuestro estudio, por lo tanto, debía partir del análisis del público lector,

10 Cfr. A. D'HAENENS, Écrive, lire et conserver des textes pendant 1500 ans. La rélation occidentale à l'écriture, kScrittura e Civiltà», VII (1983) p. 226.

"Ibidem.

12 Cfr. A. PetrucCI, Funzione della scrittura e terminologia paleografica, «PALEOGRAPHICA, DiplomaticA ET ARCHIVISTICA. Studi in onore di Giulio Battelli», Roma, 1979, I, p. 8.

13 Ibidem.
14 Ibidem. 
concretamente de las clases sociales como potenciales lectores, según su grado de participación en la cultura escrita y la forma que adopta dicha participación, lectura, escritura, posesión de libros u otros textos escritos, etc.

La primera aproximación que nos ofrece la fuente contempla la posesión del libro: las clases sociales que lo poseen y la naturaleza de los libros poseídos. Es ésta una de las limitaciones que presenta el material seleccionado: no es posible proceder a una identificación del libro poseído con el libro leido, defendida por numerosos autores que se han ocupado de este tema ". Participamos de la opinión de Maxime Chevalier, según la que la posesión de un libro no implica necesariamente su lectura, sino que puede responder a circunstancias diversas, derivadas de las distintas funciones del libro, como objeto de prestigio, representativo de unas formas culturales dominantes y unos modelos de comportamiento considerados ejemplares. La relación existente entre la posesión del libro y su lectura sólo se puede establecer con la resolución de tres interrogantes: ¿quién sabe leer?, ¿quién tiene la posibilidad de leer libros?, ¿quién llega a adquirir la práctica del libro? ${ }^{16}$.

La primera de estas cuestiones nos sitúa ante un problema aún no resuelto, la alfabetización en las sociedades del pasado y la relación entre alfabetismo y analfabetismo. De otro lado, si nos preguntamos por aquéllos que tenían la posibilidad de leer libros, nos hallamos en primer lugar ante una cuestión económica, el precio del libro, que, a su vez, nos remite a los procesos de producción y circulación de los manuscritos, y a otra índole sociocultural, la posición que el libro ocupa respecto al individuo y la actitud que éste adopta respecto a aquél, lo que depende de la forma de participación de cada individuo en la cultura escrita y de la utilización que realice de los vehículos comunicativos de que dispone la sociedad de la que forma parte.

¿Quiénes poseían libros en la Valencia bajomedieval? Los resultados obtenidos a través de la búsqueda documental coinciden con los que recogen otras investigaciones similares en otros territorios de la Corona de Aragón " clero representa más del $40 \%$ en el conjunto de los poseedores de libros. Ahora bien, no es posible considerar al estamento eclesiástico como una categoría uniforme. De hecho, se detectan grandes diferencias entre canónigos y prebendados de la catedral, y los presbíteros rectores de parroquias ${ }^{18}$, diferencias que se reflejan en su actitud ante el libro, lo que condiciona las características de su posesión. El sector correspondiente a los laicos se desglosa en los técnicos -las

1s Cfr. C. BEC, Les livres des florentins..., cit., p. 14.

${ }_{16}$ Cfr. M. ChevalieR, Lectura y lectores..., cit., p. 13.

1" Vid. nota 4.

${ }_{18}$ Cfr. M." L. Mandingorra Llavata, Leer en la Valencia del Trescientos. El libro y la lectura en Valencia a través de la documentación notarial (1300-1410). Tesis de licenciatura. Valencia, 1985, pp. 162 y ss. 
denominadas «profesiones liberales» tales como médicos, juristas...-, mercaderes, artesanos, caballeros, ciudadanos, así como mujeres. Un examen de estas cifras pone de relieve dos cuestiones: de un lado, el elevado porcentaje de clérigos poseedores de libros; de otro, la ausencia de individuos pertenecientes al medio agrario, al binterland urbano. Estos dos extremos delimitan la estratificación social de la posesión del libro. La restricción al medio urbano y el predominio absoluto del estamento clerical eran los dos aspectos que definían igualmente la difusión social de la escritura en el espacio urbano de Valencia a lo largo del siglo XV. No es posible establecer una conexión entre el conocimiento de la escritura y la posesión o lectura de libros, sin embargo, es evidente que aquéllas clases sociales que escriben son las mismas que poseen libros, aunque no nos hallemos en disposición de establecer paralelismos entre los niveles de su actividad escrituraria y sus posibles práctica y hábitos de lectura ${ }^{19}$.

El estudio de los poseedores nos conducía necesariamente al de los libros poseídos, con el fin de establecer la relación entre el poseedor y su biblioteca, tanto en el plano cuantitativo -número de manuscritos-como en el cualitativo -naturaleza de las obras que contienen-. De ese modo era posible observar los procesos de concentración y/o difusión de los manuscritos en los distintos ambientes de la sociedad objeto de estudio, según se detecte un predominio de las grandes bibliotecas o contrariamente, sean las pequeñas colecciones las mejor representadas cuantitativamente.

$\mathrm{El}$ análisis de la estructura interna de las bibliotecas partía de la identificación de las obras y los autores mencionados en la documentación recopilada, para proceder seguidamente a su clasificación en grupos que básicamente responden a las tendencias y preocupaciones culturales del momento: Derecho civil y canónico, Medicina y Ciencias Naturales, Teología y Filosofía escolástica, textos escolares de gramática, lógica y cálculo, obras de piedad, literatura de entretenimiento, clásicos... ${ }^{20}$.

Los libros que aparecen en los inventarios localizados responden básicamente a dos polos de atracción cultural. De un lado, un amplio sector revela una cultura técnica, escolástica, fundamentada en las disciplinas universitarias: Medicina, Derecho, Teología, junto a Trivium y Quadrivium ocupan buen parte de las bibliotecas, no sólo de eclesiásticos o profesionales de la Medicina o el Derecho, sino también de mercaderes y artesanos, a quienes el desarrollo de su

19 Cfr. M.* L. Mandingorra Llavata, La escritwra al servicio de la administración municipal. La acumulación snifica de los Hospitabes valonciemos (1400-1509). Tesis de licenciatura. Valencia, 1985, Pp. 162 y ss.

20 Esta división es puramente arbitraria, sus términos no pueden ser considerados categorías, tan sólo un instrumento de clesificación. 
actividad exige conocimientos concretos en el terreno de la gramática, del cálculo, etc. Por otra parte, la presencia de los libros religiosos y devocionales en las bibliotecas de particulares, especialmente laicos, es fruto de la renovación de las formas de la piedad en los siglos finales de la Edad Media y del progresivo acceso de aquéllos a los textos sagrados, a través de una lectura devocional destinada a fomentar una meditación individual e íntima ${ }^{21}$. Pero el libro piadoso no sólo es testimonio e instrumento de una nueva religiosidad, sino la primera expresión de la lectura de entretenimiento. Finalmente, las obras literarias apenas si gozan de representación en las bibliotecas privadas. En la mayor parte de los casos se trata de obras en lengua vulgar, presentes en bibliotecas de mercaderes y artesanos.

El análisis de los libros y sus poseedores nos conducía al de los vínculos que se establecen entre ambos, en especial la lectura y sus distintas modalidades ${ }^{22}$. La lectura, como técnica, no es sino la decodificación de un mensaje escrito, sin la que no se produce el acto de comunicación. Así, la capacidad de lectura de un individuo podría identificarse con su grado de habilidad para decifrar los signos gráficos que componen el mensaje. Sin embargo, la lectura, en cuanto forma de comprensión lingüística se articula en dos niveles, al igual que sucede en el caso de la escritura. La lectura superficial es aquélla que permite decodificar el mensaje escrito, pero no así captar su textualidad. La lectura profunda posibilita una comprensión total del texto escrito, y exige un grado de competencia lingüística superior que permita un control de la textualidad escrituraria ${ }^{23}$.

Las distintas funciones que asume la lectura individual generan otras tantas modalidades en el seno de la misma. Una de ellas es la lectura de textos administrativos, como por profesionales -notarios, escribanos, funcionarios...como por particulares que proceden a su lectura por motivos de carácter laboral. Se trata sobre todo de mercaderes y artesanos cuya actividad les exige una competencia de lectura y escritura que puede alcanzar incluso niveles que les permitan generar sus propios textos ${ }^{24}$. Esta modalidad de lectura tiene por objeto documentos de naturaleza económica procedentes de cualquier oficina de expedición documental, textos administrativos de naturaleza pública y todo

${ }^{21}$ Cfr. G. DuBY, Tiempo de Catedrales. El arte y la sociedad. 980-1420, Barcelona, 1983, pp. 298- 299.

${ }_{22}$ La lectura no es el único vínculo que se establece entre el libro y el individuo. La posesión del libro, por sí misma, puede cumplir una función social, por ejemplo cuando se trata de libros de lujo, de alto precio, en los que su papel de status-symbol predomina sobre su valor instrumental.

${ }^{23}$ Cfr. R. SIMONE Scrivere, leggere, capire, «Quaderni Storiciw, 28 (1978), pp. 666 y ss.

${ }^{24}$ Vid. entre otros, C. BEC, Les marchands écrivains..., cit.; F.M. GIMENO BLAY-M.' T. Palasí Fas, Del negocio y del amor. El Diario del mercader Pere Seriol (1371), «Saitabi», XXXVI (1986), pp. 37- 55; L. MIGLIO, L'altra metà della scrittura: Scrivere il volgare (alle origine delle corsive mercantili), «Scrittura e Civiltà», X (1986), pp. 83-114. 
tipo de documentación privada de índole económica, incluída la correspondencia -libros de cuentas, albaranes autógrafos o escritos por intermediarios gráficos... etc.-. En esta modalidad de lectura existen muchos casos de lectura superficial, ya que cada tipología documental presenta unas fórmulas invariables que en el caso de la documentación de naturaleza económica suelen responder a esquemas estereotipados que se repiten, lo que facilita su lectura, al menos a aquéllos individuos que se han familiarizado con ellos.

Otra modalidad de lectura en la que se detectan casos de lectura superficial es la lectura devocional o piadosa, particularmente cuando se desarrolla con el complemento de la imagen, necesario apoyo para la comprensión del texto ${ }^{23}$; puede quedar inclusive limitada a la lectura de las palabras o frases que suelen acompañar a la imagen, por ejemplo, en las filacterias ${ }^{26}$, sin proceder a la lectura del texto propiamente dicho.

La lectura piadosa se hallaba muy difundida entre todas las clases sociales que habían adquirido una capacidad de lectura incluso cuando ésta se situaba a muy bajo nivel. Mercaderes y artesanos, para quienes la lectura, al igual que la escritura, era primordialmente un instrumento al servicio de su actividad profesional, se servían de ella, sin embargo, con una finalidad devocional que guardaba una muy estrecha relación con sus actividades económicas, como justificación de las mismas ${ }^{27}$.

Por otra parte, la lectura de estudio es una lectura profunda, comprensiva ${ }^{28}$. Por su naturaleza en ella no cabe un simple mecanismo de decodificación de signos, puesto que exige una total comprensión del texto leído. En el período que nos ocupa, la lectura de estudio tiene un marcado carácter profesional, porque se vinculaba a determinadas actividades cuyo adecuado desenvolvimiento no se concibe sin un conocimiento profundo y práctico de la lectura, circunstancia ésta propia de los juristas, médicos, e incluso, del clero. La lectura de estudio requiere, junto al dominio de la mecánica de la decodificación de los signos, unos conocimientos específicos de la materia objeto de lectura.

Existe, no obstante, una lectura de estudio no profesional, que se halla en relación con la lectura de entretenimiento. Individuos que gozan de una formación cultural que les permite abordar la lectura de textos de muy diversa índole, leen obras científicas sin que esta actividad encierre un fin profesional, ya que tratan de temas que no guardan relación alguna con su trabajo. La

25 Vid. F.M. Gimeno Blay-J. Trenchs Odena, Escritura: Palabra e Imagen. Reflexiones sobre la cultura escritra reproducida, "Anales de la Universidad de Alicante. H." Medievalw, 4-5 (1986), pp. 359-378.

${ }^{26}$ Ibidem.

27 Cfr. C. BEC, Les marcbands écrivains..., cit., pp. 393-394.

${ }^{28}$ Es la que Escarpit denominaba lectura objetiva. Cfr. R. EsCARPIT, Escritura y comunicación, trad. castellana, 1975, pp. 60-65. 
curiosidad por la Astrología, las ciencias naturales, la medicina inclusive, se refleja en las bibliotecas, y en el caso de la Astrología, por ejemplo, se confirma con la presencia de instrumental relativo a esta disciplina, junto a los libros que integran la biblioteca. Esta forma de lectura, con todo, tenía una escasa difusión en la sociedad valenciana del XIV.El interés que por la adquisición de libros, y en particular, de textos científicos, se manifiesta en la Corte de los monarcas catalano-aragoneses de la época, no debe llevarnos a engaño, ya que esta preocupación apenas si conoce una dimensión mayor que el ambiente de la Corte y la Cancillería ${ }^{29}$.

Un estudio relativo a la lectura no puede dejar de contemplar las estructuras materiales que la hacen posible: el libro y la biblioteca. Ambos son, asímismo, resultado de la necesidad de leer, y en el caso de la biblioteca, de la voluntad de acumular y conservar un producto escrito, el libro.

El estudio del libro como estructura material es el de las tipologías librarias. El incremento en el volumen de la producción escrita, la multiplicación y diversificación que experimentaron los mecanismos de la producción del manuscrito, fruto del aumento en la demanda de libros, dieron lugar a una gran variedad de formas librarias difícilmente tipificables. Las clasificaciones realizadas por los estudios se basan habitualmente en la funcionalidad como criterio ordenador, ya que la función que unlibro debe desempeñar determina sus caracteres materiales y se halla en relación directa con el encargo que efectúa un particular o una institución.

El libro de lujo es aquél en el que la función de status-symbol predomina sobre las demás. El libro de lujo propiedad de las instituciones religiosas se caracteriza habitualmente por su formato grande, la utilización del pergamino como materia escritora, la encuadernación de madera forrada de cuero o terciopelo. El tipo gráfico predominante en su confección es la gótica textual. Es el libro de coro, el Misal, frecuentemente ornamentado ${ }^{30}$. En cambio, el libro de lujo propiedad de particulares suele ser de formato medio o pequeño -cuarto, octavo...-. Su factura es similar a la del anterior, en materiales,

29 Vid. A. Canellas López-J. Trenchs Odena, Cancilleria y cultura. La cultura de los escribanos y notarios de la Corona de Aragón, «Folia Stuttgartensiaw, Zaragoza, 1988.

${ }^{30} \mathrm{Cfr}$. A. PETRUCCI, Alle origini del libro moderno. Libri da banco, libri da bisaccia, libretti da mano, en IDEM, Libri, scrittura e pubblico nel Rinascimento, Bari, 1979, p. 145. 
iluminación, etc. Cabe señalar, sin embargo, la utilización en estos manuscritos de la minúscula cancilleresca; es el libro-registro de lujo que conocía una cada vez mayor difusión social ${ }^{31}$. Se trataba frecuentemente, de libros litúrgicos o devocionales, en especial la Biblia o las Horas, aunque también existen ejemplares de obras jurídicas, como los Fueros de Valencia o el Sexto ${ }^{32}$.

En el libro-instrumento, por el contrario, predomina su función como útil de estudio o trabajo. Es el que se halla cuantitativamente mejor representado en el total de volúmenes citados en la documentación, si bien a este predominio no corresponde una difusión social amplia, sino que, contrariamente, su presencia queda restringuida a los profesionales del Derecho o la Medicina y a parte del clero.

El libro-instrumento es un libro de uso. De acuerdo con ello, suele ser de formato medio, y sólo ocasionalmente, grande. La materia escritora predominante es el pergamino, siendo escaso el papel, aunque su presencia irá en aumento a lo largo del siglo. Las encuadernaciones utilizadas son muy diversas, lo mismo que los tipos gráficos que aparecen mencionados en los documentos. La iluminación no es frecuente, aunque disponemos de algunos testimonios de su presencia en estos manuscritos.

El libro-instrumento es objeto de una lectura de estudio, sus propietarios son médicos, juristas, notarios... que se sirven de él como instrumento necesario para el adecuado desenvolvimiento de su profesión. El interés que manifiestan por su conservación y, sobre todo, por su transmisión en el seno de la familia, es prueba de la importancia atribuída a estos libros, como testimonio de la pertenencia a una categoría socioprofesional ${ }^{33}$.

Bajo la influencia de la Historia de las mentalidades, se tiende en la actualidad a dividir la producción del libro bajomedieval en dos grandes grupos, el libro docto o culto y el libro popular, de acuerdo con el público al que iba dirigido. Esta escisión, que se basaba en el aspecto exterior delligro fue en aumento, hasta que el advenimiento de la imprenta contribuyó a su canonización ${ }^{34}$. Sin embargo, esta denominación plantea diversos problemas, entre ellos, la ambigüedad del adjetivo popular, en cuanto que define tanto lo que es propio

31 Es el libro de lujo burgués de que habla Luisa MIGLIO en Considerazioni ed ipotesi sul libro 'borgbese' italiano del Trecento. A proposito di un'edizione critica dello 'Speccbio umano' di Domenico Lenzi, «Scrittura e Civiltà», III (1979) pp. 309-337.

32 Cfr. M.: L. MandingorRa Llavata-J. TrenchS, Juan Fermández de Porto y su biblioteca juridica (1383), «Saitabi», XXXVIII (1988) pp. 74-75.

${ }^{33}$ M.' L. MandingorRa Llavata, Leer en la Valencia del Trescientos..., cit., pp. 8081.

${ }^{4}$ Cfr. A. PetruCCI, Per una nuova storia del libro, introducción a la traducción italiana de L. FebVRe-H. MARTIN, L'apparition du liure, Roma-Bari, 1977, pp. XXXI y ss. 
del pueblo, como lo que emana del mismo o lo que es de su especial agrado ".

Es por este motivo que resulta especialmente difícil hablar del libro popular, también denominado libro burgués. El uso de este término se apoya en el hecho de que este libro se halla presente fundamentalmente en las bibliotecas de los burgueses de la ciudad ${ }^{36}$. El surgimiento de esta tipología libraria fue consecuencia de la renovación de la demanda que produjo el progresivo acceso a escritura y lectura por parte de grupos sociales que hasta entonces habían permanecido al margen de las mismas ". Si bien este libro presenta unas características formales que son comunes a todos los ejemplares, se define básicamente por una concepción única en su origen. Sus contenidos eran muy diversos, ya que en muchos casos es el resultado de una vulgarización de modelos. El libro-burgués puede ser devocional, literario, técnico... pero siempre destinado a una lectura privada, de meditación o esparcimiento.

En general el libro-burgués era de bajo precio: su formato era pequeño o medio; la materia escritoria utilizada era habitualmente el papel, la encuadernación solía ser de pergamino. Aparece tanto de forma aislada, como integrando bibliotecas de marcado carácter profesional, y por tanto, constituídas fundamentalmente por libros de estudio. Por sus características, tanto como por su función, se hallaba sujeto a pérdidas y deterioro en mayor medida que las restantes tipologías librarias ${ }^{38}$, especialmente cuando se trataba de manuscritos que contenían obras técnicas o escolares ${ }^{39}$. Por otra parte, la circulación de estos libros, básicamente a través de préstamos, donaciones, etc., favorecía su dispersión y pérdida ${ }^{40}$.

35 Vid. G. DEMERSON (dir.) Livres populaires du XVle siècle. Répertoire sud-est de la France, Paris, 1986, p. 6.

${ }^{16} \mathrm{Al}$ hablar de burgueses nos referimos a ese grupo social juridicamente encuadrado en el estamento popular, pero bien diferenciado dentro de éste, tanto por las actividades profesionales de sus miembros, como por su riqueza y medios de vida. Cfr. A. Rubio VeLA, Epistolari de la València medieval. Valencia, 1985, p. 11. El mismo Agustín Rubio recoge la definición dada por Eiximenis de la segona mà o mà mitjana:

... sots aquesta mà se comprenen comunament juristes, notaris, mercaders e drapers poderosos, e tots aquells qui sens generositat notable han grans riquees en la ciutat.

${ }^{37}$ Vid. M." L. Mandingorra Llavata, Leer en la Valencia del Trescientos..., pp. 149-155.

${ }^{38}$ Indudablemente, el precio del libro es, junto con su valor estético-artístico, al que va unido, un elemento clave en la conservación o no del mismo, particularmente, debido a intereses bibliológicos.

30 Cfr. B. LAURIOUX, Un exemple de livre technique: les livres de cuisine à la fin du moyen âge, "Gazette du livre médiéval», 14 (Printemps 1989), pp. 12-13.

4) Son frecuentes las menciones en testamentos e inventarios, de libros prestados o 
Al hablar de las bibliotecas medievales debemos olvidar las definiciones actuales del término biblioteca y considerar la pluralidad de significados que encierra ${ }^{41}$ en cuanto que es el resultado, tanto de la posesión del libro, como de la necesidad de leer y la voluntad de acumular y conservar la información contenida en aquél. En este sentido, su historia se vincula a la historia del libro, ya que la historia de la biblioteca es la historia del libro en su función social, cultural e ideológica, y en su dimensión, no de objeto independiente, sino de elemento de un amplio engranaje, que cumple una concreta función sociocultural. Su definición, por consiguiente, no es ni puede ser unívoca, sino múltiple, y su estudio debía contemplar todos sus aspectos: su dimensión espacial, funcionalidad, estructura interna y relación con su poseedor/usuario.

El término biblioteca se utiliza en la mayor parte de los casos para denominar a las colecciones de libros pertenecientes a instituciones. Al hablar de bibliotecas de instituciones nos referimos a instituciones religiosas ${ }^{42}$, que en la Baja Edad Media aportaron un nuevo modelo de biblioteca, completamente diferente al altomedieval -caracterizado por los binomios archivo/biblioteca y biblioteca/scriptorium ${ }^{43}$ - . Esta nueva biblioteca era asímismo urbana y abierta, y se encontraba estrechamente ligada a los ambientes universitarios.

Las bibliotecas de las instituciones se caracterizan por su homogeneidad. En la mayor parte de las iglesias la biblioteca quedaba restringida a los libros necesarios para la celebración del culto. En cambio, las sedes catedralicias y las Órdenes monásticas poseían grandes bibliotecas que se dividían en dos secciones, la correspondiente a los libros litúrgicos, de carácter monumental o no, y la integrada por los libros que contenían textos universitarios, esto es, las obras de lectura y estudio, a su vez dividida en biblioteca de consulta y biblioteca circulante.

La existencia de un espacio destinado a la custodia de los libros es uno de los factores que garantizaban la conservación de la biblioteca institucional, ya que permitía ejercer un control sobre los mismos. Por otra parte, el respaldo institucional la ponía a cubierto de los peligros de dispersión: la perdurabilidad de la institución garantizaba la de los manuscritos, a través de mecanismos de custodia y, en su caso, de sustitución. La biblioteca institucional no experimentaba los procesos de transmisión a que se veían sometidas las bibliotecas de

dejados en prenda. Cfr. M.* L. MandingorRa Llavata, Leer en la Valencia del Trescientos..., cit., documentos 31 y 65 del Apéndice.

4l Acerca de la multiplicidad de significados que encierra el término biblioteca, en particular en el mundo antiguo y medieval, vid. G. CAVALLO, Le biblioteche nel mondo anticoe medievale, premessa, Roma- Bari, 1988, p. VII.

${ }^{42}$ Desgraciadamente la documentación analizada no nos ha aportado información alguna sobre bibliotecas de instituciones laicas, ya fueran municipales o reales.

${ }^{43}$ Cfr. G. Cavallo, Le biblioteche..., cit., p. XXV. 
particulares; su existencia era un contiuum, en el que incluso la circulación de sus libros se realizaba bajo un estricto control.

Las bibliotecas de particulares presentan mayor complejidad en su análisis, ya que no siempre participaban de los esquemas de las bibliotecas institucionales, consideradas siempre representativas de la biblioteca como entidad. De un lado, encontramos bibliotecas tipificadas, altamente especializadas en ocasiones, que contienen obras relativas a la actividad profesional de su propietario. Es la biblioteca que hemos denominado técnica, la biblioteca del docto -clérigos, juristas, médicos...- proyección de la gran biblioteca de consulta de las instituciones religiosas ${ }^{44}$. Por otra parte, hallamos las bibliotecas no especializadas, propiedad de mercaderes, artesanos, ciudadanos dedicados a actividades financieras diversas, a la oligarquía urbana, en suma. Estas bibliotecas se caracterizaban por su heterogeneidad, tanto en su volumen, como en su composición. Entre ellas encontramos desde las pequeñas colecciones de dos o tres libros de naturaleza religiosa, a las grandes bibliotecas que incluyen, junto a los libros devocionales, obras literarias, textos de gramática, lógico, cálculo... etc.

Las bibliotecas técnicas, al igual que las pertenecientes a instituciones, responden, tanto en su repertorio como en su ordenación interna y en su utilización a la cultura universitaria y al métido escolástico. La mayor parte de los libros que las integraban eran útiles de estudio, aunque también contaban con manuscritos de lujo, o con otros que contenían obras literarias, habitualmente de papel y escaso valor ${ }^{45}$. La homogeneidad de su composición deriva del carácter instrumental que se atribuye al libro. La vinculación de la biblioteca a la actividad profesional de su propietario la convertía en signo de pertenencia a una clase social, de adscripción a ciertos valores y formas de comportamiento... cuya transmisión en el seno de la familia iba unida a la del patrimonio económico.

Existen asísmismo bibliotecas especializadas que no guardan relación directa con el mundo universitario. Se trata de colecciones habitualmente pequeñas, pertenecientes a individuos cuya formación es fundamentalmente práctica, como notarios, veterinarios, boticarios, cirujanos... e integradas por manuales y tratados prácticos y no por obras de naturaleza teórica.

Por otra parte, las bibliotecas no especializadas presentan estructuras diversas que responden a intereses concretos de sus propietarios.

Los textos escolares se destinaban a la formación elemental, previa a la

${ }^{14}$ Cfr. A. Petrucci, Le biblioteche antiche, en «Letteratura Italiana Einaudi, II Produzione e consumo», Torino, 1983, p. 534.

4s De hecho, en ocasiones, los compiladores del inventario no relacionaban estos volúmenes y se limitaban a mencionar su existencia, bien individualmente, bien en grupos. 
formación profesional de su poseedor. Las nuevas formas de vivir la religiosidad, íntimas e interiorizadas que se generalizan enlos siglos XIV y XV explican la gran difusión del libro devocional, objeto de la única forma de lectura común al público lector de la Baja Edad Media.

La lectura devocional, al igual que la de entretenimiento no eran sino manifestaciones de la lectura «libre» -aquélla que se desarrollaba fuera del lugar destinado al estudio-. La lectura libre nació como actividad del clérigo al margen de la disciplina oficial y se extendió rápidamente también a los laicos, quienes la canalizaron hacia sus particulares intereses, de índole religiosa, cultural o profesional. Su difusión constituyó la base del proceso de generalización de una lectura en vulgar por parte de individuos que no conocían la lengua latina, y que podía convertirse en lectura herética de textos heréticos ${ }^{46}$.

El análisis de las bibliotecas de particulares nos obliga a considerar diversos aspectos, el primero de ellos, la cuestión del espacio, el lugar o lugares que los libros ocupaban en la casa y su relación con la funcionalidad que desempeñaban. No todos los inventarios mencionan el lugar en que fueron hallados los libros, y cuando lo hacen, nada nos asegura que no hubieran sido colocados allí con posterioridad a la muerte de su poseedor, como atestiguan algunos documentos ${ }^{47}$. Evidentemente, las bibliotecas de los particulares valencianos del XIV no poseen un espacio físico propio, sino que éste varía dependiendo de los individuos. Incluso una biblioteca puede aparrecer distribuída en diversos puntos de la casa: la biblioteca como espacio no existe.

La biblioteca técnica suele hallarse en la habitación en que su dueño desarrollaba su actividad. Así era en el caso de la biblioteca del jurista Juan Fernández de Porto. Los libros que utilizaba en sus actividades cotidianas se encontraban en el estudio, en el que se encontraba asímismo un «arquibanch gran de plega, del qual lo dit defunt feya estudi e en lo qual tenia les rodes» ${ }^{48}$. Los libros no eran sino una parte más del espacio laboral de su poseedor. En cambio, los libros de contenido religioso, el Libro de Horas, no participaba de este espacio profesional, sino que se conservaba en el dormitorio del difunto, un espacio apto para la lectura de que era objeto, una lectura privada, de meditación.

El obrador es, en el caso de los mercaderes y artesanos, el espacio propio de los libros de administración o de memorias, ya que así lo exige su función y uso ${ }^{49}$, aunque existan ejemplos de la presencia de estos libros en otros lugares

${ }^{46}$ Cfr. A. PetruCCI, Le biblioteche antiche, cit., p. 543.

${ }^{47}$ Cfr. M. ${ }^{2}$ L. Mandingorra Llavata-J. Trenchs Odena, Juan Fernández de Porto y su biblioteca juridica, cit., p. 69.

${ }^{48}$ Ibidem, p. 70.

49 Cfr. M." L. MAndingorra Llavata, Leer en la Valencia del Trescientos..., , cit., pp. 220-223. 
de la casa. Junto a los libros de administración, el obrador puede acoger también los de contenido moral o piadoso. La lectura de textos religiosos se hallaba relacionada estrechamente en ocasiones con las actividades profesionales de los individuos que la ponen en práctica: aún en los siglos XIV y XV el trabajo sigue siendo una mácula servil, particularmente, si se trata de trabajo manual. De hecho, los primeros manuales de confesores traducidos a lenguas vulgares -y destinados al uso de los laicos- eran los que con mayor intensidad trataban los casos de conciencia de aquéllos que ejercían un oficio, como la Summa de Iohannes de Friburgo ".

La desconfianza de la Iglesia hacia el mundo de los oficios, el control que sobre él ejercía por medio de su vida corporativa, creaban en estas clases sociales la necesidad de una práctica religiosa que debía desarrollarse en todas sus vertientes y la lectura ofrecía una vía para esta práctica ${ }^{\text {'1 }}$.

La ausencia de un espacio único muestra la falta de una conciencia de la biblioteca como entidad. Sólo en algunos casos se advierte una voluntad de conservar la biblioteca como tal, siempre entre miembros del clero o profesionales de la medicina o el Derecho. Una prueba de ello son las condiciones de conservación de los libros en cofres, armarios, arquibancos... acompañados a veces por otros textos escritos -documentos-, pero también al lado de objetos de muy diversa naturaleza.

Del mismo modo, la falta de una noción de biblioteca se refleja en los procesos de transmisión. De hecho, al hablar de los mecanismos de la misma refiriéndonos al libro, es difícil discernir si se trata de transmisión del libro o de la biblioteca, ya que en la época no se diferenciaba entre ambos. La transmisión del libro, de la biblioteca, podía producirse de diversas formas. La más frecuente era a través de la herencia. Los libros formaban parte del conjunto de los bienes que pasaban al heredero universal, en cuyo caso, el testamento no realizaba mención alguna de ellos, o bien constituían legados particulares, que revelan el interés del propietario por el destino de sus libros.

Los legados podían afectar al total de la biblioteca, a parte de la misma o a un solo volumen. Aunque no permiten conocer la totalidad de aquélla, posibilitan como contrapartida conocer la identidad del destinatario, e incluso los motivos que indujeron al poseedor a disponer dicho legado. En algunos casos el testador consideraba importante mencionar sus libros entre los objetos que constituían el conjunto de bienes destinado al heredero universal. ¿Es esto una prueba del valor atribuído al libro? Es difícil saberlo. El médico Sanxo del

so Cfr. J. LE GoFf, Oficio y profesión según los manuales de confesores de la Edad Media, en IDEM, Tiempo, trabajo y cultura en el Occidente medieval, trad. cast., Madrid, 1983, p. 172.

"Cfr. C. BEC, Les marchands écrivains..., cit., pp. 393-394. 
Miracle dejó todos sus libros a su hijo mayor, Bernat, pero en su testamento precisaba que éstos debían pasar, en el caso de que Bernat falleciera sin hijos legítimos, a su hermano Joan, y del mismo modo, si éste muriera sin descendencia, al menor de los hermanos, Miquel. El testamento relaciona minuciosamente todos los libros de medicina; sin embargo, los libros de lógica y gramática son mencionados globalmente. De hecho su destino debía ser diferente al de las obras médicas, ya que pese a que formaban parte del legado total de libros, el testador dispuso que debían pasar de uno a otro de los hermanos, según concluyeran su formación escolar. Evidentemente, los libros de medicina, signo de su categoría socioprofesional, eran mucho más valiosos para Sanxo del Miracle que los de lógica y gramática, destinados a la formación elemental ${ }^{32}$.

Es éste uno de los pocos casos en que un laico revela, a través de su actuación, un interés por mantener intacto un patrimonio librario. Hay que reseñar que algunos de sus libros los había heredado de su hermano Miquel, de forma que los volúmenes continuaban en el seno de la familia, en un proceso que formaba parte de la transmisión del patrimonio económico y sociocultural.

Los cambios que afectan a las bibliotecas al pasar de padres a hijos constituyen elementos que permiten realizar el análisis de la evolución de la familia, de los procesos de promoción social "3. Entre los particulares laicos del Trescientos la conservación de una biblioteca heredada es testimonio de una continuidad socioprofesional, ya que estas bibliotecas carecían del carácter conservador que define a las bibliotecas señoriales. En el caso de las bibliotecas técnicas, los libros recibidos en herencia sólo se conservaban si perduraba su función, es decir, si constituían un útil de estudio para su nuevo propietario. Es por ello que la dispersión de una biblioteca de estas características testimonia una ruptura en la actividad profesional e incluso en el nivel social de la familia ${ }^{54}$.

El caso de los clérigos presenta ciertas similitudes con los anteriores, en lamedida en que las bibliotecas de los eclesiásticos son bibliotecas especializa-

"2Vid. M." L. MANDingorRa LlavaTa., Leer en la Valencia del Trescientos..., cit., pp. 80-81.

${ }_{33}$ Ello es especialmente interesante en el caso de las familias que experimentaron un proceso de ennoblecimiento a lo largo del siglo XV. Las bibliotecas técnicas propias de médicos y juristas fueron sustituídas, al adquirir la condición nobiliar, por otras en las que predominaban los libros litúrgicos y devocionales, como la de la Lluís Vallseguer, hijo y nieto de notarios, que no conservaba a su muerte los libros que fueron de su padre, Jaume Vallseguer, que, a su vez, los había heredado el suyo, Cfr. M. ${ }^{a}$ L. MANDINGORRA LlaVATA, Leer en la Valencia del Trescientos..., cit., p. 91.

s4 Ibidem. 
das, vinculadas a su actividad profesional. En el clero se advierte una honda preocupación por asegurar el traspaso de los volúmenes que juzgaban más importantes, los que sólo cobraban significado en manos de un eclesiástico, como el Misal o el Brevario".

El legado individualizado de estos libros constituía, sin embargo, un factor de disgregación de las bibliotecas, ya que, frecuentemente, el resto de los libros pasaba a otras manos. En muchos casos el legado de libros representaba el pago de un servicio o de una deuda. El factor económico influía sin duda en la transmisión de los manuscritos, ya que, si bien el precio de los mismos podía oscilar mucho, la venta de una biblioteca podía reportar una suma considerable.

La venta en almoneda era especialmente frecuente y ofrecía la posibilidad de comprar libros a bajo precio. Estas prácticas favorecían la dispersión de las bibliotecas, pero, al mismo tiempo posibilitaban la circulación de los libros, aunque en general ésta se producía en ambientes claramente acotados ${ }^{56}$.

La transimisión de los libros se producía asímismo por medio de ventas y donaciones entre privados. El análisis de las mismas revela igualmente una circulación en ambientes delimitados. La existencia de estas prácticas y el elevado precio alcanzado por los manuscritos han sido considerados una prueba de la escasez de libros disponibles frente a la demanda que se incrementaba a lo largo de los siglos XIV y XV. Con todo, si realmente existía una carencia de libros, cabría preguntarse a qué niveles se producía, ya que los manuscritos que alcanzaban un precio mayor eran los libros litúrgicos de lujo o ciertos textos universitarios; en cambio, era posible adquirir a bajo precio libros de lectura devocional, de entretenimiento o de divulgación.

En general, no se puede hablar de transmisión de la biblioteca, sino del libro. Se advierte una preocupación por ellibro como objeto de valor económico, intelectual o sociocultural, siempre presidida por la conexión libro/ individuo. Era precisamente esta concepción individual del libro -que hacía posible su conservación- el principal agente que actuaba en contra de la biblioteca como entidad.

La biblioteca como estructura no existe en el sistema de valores del hombre del Trescientos ". Existe el libro, su función y el uso que de él se realiza. Se procura su conservación, pero no con el fin de constituir una biblioteca. Se

${ }^{6}$ Por ejemplo, la mayor parte de los libros del jurisperito de Játiva Durant de Listó, a cuya venta precedieron Joan d'Albis y Bertomeu de Torres, fueron comprados por profesionales del Derecho. Asímismo, los libros del canónigo Guillem Oller fueron adquiridos por eclesiásticos. Vid. M." L. MANDingorRa Llavata, Leer en la Valencia del Trescientos..., cit., documentos 49 y 71 del Apéndice.

${ }^{37}$ Ibidem, pp. 248 y ss. 
cuida su traspaso, pero es éste uno de los principales vehículos de dispersión de las colecciones. El término biblioteca es, por tanto, funcional, ya que salvo las excepciones correspondientes a las bibliotecas de instituciones, no existe en las representaciones mentales de la época.

Se advierte, por lo tanto, que el libro y su lectura eran, en este período, un fenómeno urbano, particularmente por lo que a los laicos se refiere, aunque su presencia en este medio fuera escasa cuantitativamente, y muy difernciada, dependiendo de las clases sociales.

No es posible en el estado actual de nuestros conocimientos individualizar a los lectores de libros, pero sí podemos señalar algunas características del público potencialmente lector. De un lado, hallamos un amplio sector constituído por todos aquéllos -laicos o eclesiásticos- que habían recibido una formación universitaria. Para ellos escritura y lectura eran dos útiles necesarios de estudio y trabajo, como también lo era el libro. Su lectura, por consiguiente, se definía por su carácter instrumental, y se desarrollaba tanto en lengua latina, como en vulgar. Su formación se iniciaba en las escuelas, donde el aprendizaje de lectura y escritura seguía el de la gramática y la lógica. Hay que señalar con todo la diferencia entre aquéllos que habían cursado estudios universitarios -que habían recibido una formación teórica de la que ellibro era instrumento indispensable- y aquellos individuos cuyas profesiones se fundamentaban en una formación práctica, que mantenían con el libro una relación puntual, debido al carácter práctico de su preperación profesional.

Frente a este sector del público se encontraban los grupos tradicionalmente no vinculados a la cultura escrita, pero que progresivamente, a través de un proceso de apropiación, accedían a la escritura, el útil de gestión administrativa que precisaban en sus negocios, y a la lectura, como sistema de decodificación de aquélla: mercaderes y artesanos. Su formación se desarrollaba de forma endogámica, en el seno de la familia o de su entorno profesional, aunque a lo largo de este período se produjo de modo paulatino su acceso poración a las escuelas de lógica y gramática. Así, en origen, su aprendizaje de la lectura no tenía por objeto el libro, sino el documento, la carta, el texto administrativo.

En todo caso, tenía lugar un fenómeno común a todo el público lector: el acceso a la lectura y a la escritura, ya se produjera a través de la escuela o de forma endogámica en el seno de la familia o del grupo profesional, se debía en origen a una necesidad práctica inmediata, diferente según los casos: estudios universitarios, celebración de la liturgia, funcionamiento de una botiga... etc. 
Sin embargo, esta capacidad fue rápidamente desviada de sus primitivos fines hacia nuevos objetivos, de naturaleza privada, personal, que no guardaban relación alguna con las iniciales motivaciones que les habían conducido al aprendizaje de estas técnicas. Fruto de este mecanismo de desviación fue la lectura libre, que se difundió entre laicos y eclesiásticos y se convirtió en uno de los principales agentes que motivó el incremento de la producción y diversificación de la demanda de libros enlos siglos bajomedievales, y que a su vez, dio lugar a una mayor complejidad en los procesos de producción libraria.

Es por este motivo que la cultura a que remiten los libros localizados e identificados es una cultura técnica, profesional, estrechamente vinculada al mundo universitario en el caso de médicos, juristas y parte de los eclesiásticos, y tradicional en todas las ocasiones. Junto a una formación profesional conservadora hallamos otro polo de atracción, definido por la vida religiosa. Así, formación profesional por medio del estudio de textos tradicionalmente considerados como válidos y edificación del espíritu a través del conocimiento de textos devocionales, fuente de formas de comportamiento «ejemplares», son los referentes que dominan el programa textual de los libros que integraban las bibliotecas del XIV. La presencia de los clásicos es muy restringida. La literatura no religiosa, siempre en lengua vulgar, es propiedad de burgueses y se limita a libros de poesías y novelas de caballería que proponen modelos socioculturales a imitar y actitudes mentales a asumir.

El libro se muestra así como un vehículo comunicativo que forma parte de un engranaje más amplio constituído por todos los signos de la ciudad, cuantitativamente poco representativo -su difusión social es escasa- pero de gran peso cualitativo, dado que recoge, conserva y transmite los modelos culturales dominantes a que remite el conjunto de la sociedad, participe o no de ellos.

Como vehículo comunicativo, el libro se halla dotado de un valor instrumental, que lo vincula directamente al individuo que lo posee. Su conservación depende tanto del factor económico -el precio- como de la naturaleza del vínculo que establece con su propietario, y, por consiguiente, de la función que asume. Los procesos y mecanismos de conservación y transmisión de los volúmenes ponen de manifiesto no sólo su importancia económica, sino también su papel en el engranaje comunicativo de la sociedad como objeto individual, testimonio de la pertenencia a una categoría social y de la adscripción a determinadas formas de comportamiento, y revelan igualmente la ausencia de la noción de biblioteca como ente, que sólo existe en el plano institucional.

M." LUZ MANDINGORRA LlavaTA Universidad de Valencia 


\section{CUADRO I}

Distribución cuantitativa de los poseedores de libros según su categoría socioprofesional

CLERO

JURISTAS Otros

NOTARIOS

MÉDICOS

$9,7 \%$

MERCADERES

ARTESANOS

CIUDADANOS

CABALLEROS

MUJERES

SIN IDENTIFICAR

\section{CUADRO II}

Distribución de las bibliotecas según su volumen y la categoría socio-profesional de su propietario

1-5 vol. 6-10 vol. 11-20 vol. 21-30 vol. más de 30 vol.

$\begin{array}{lccccc}\text { CANÓNIGOS } & 22,2 \% & 22,2 \% & 22,2 \% & - & 33,3 \% \\ \text { PRESBÍTEROS } & 62,5 \% & - & - & 37,5 \% & - \\ \text { OTROS CLÉRIGOS } & 28 \% & - & 28 \% & - & 43 \% \\ \text { JURISTAS } & 33 \% & - & 33 \% & - & 33 \% \\ \text { NOTARIOS } & 60 \% & 20 \% & 20 \% & - & - \\ \text { MÉDICOS } & - & - & - & 100 \% & - \\ \text { BOTICARIOS } & 100 \% & - & - & - & - \\ \text { CIUDADANOS } & 75 \% & 25 \% & - & - & - \\ \text { MERCADERIES } & 25 \% & 25 \% & 25 \% & - & 25 \% \\ \text { ARTESANOS } & 100 \% & - & - & - & - \\ \text { MUJERES } & 100 \% & - & - & - & - \\ \text { CABALLEROS } & 100 \% & - & - & - & -\end{array}$




\section{RÉSUMÉ}

Cet article tend à faire ressortir certains aspects en rapport avec la recherche sur le livre et ses différentes utilisations, en particulier les diverses significations de la possession d'un livre par les particuliers: le livre en tant qu'instrument de travailétude, le livre en tant qu'élément constitutif d'un espace dédié à la dévotion, le livre en tant que distraction... Chacune de ces significations témoigne d'une attitude de l'individu qui possède un livre par rapport à la culture écrite et surtout par rapport au rôle que celle-ci joue dans la consolidation de son statut social.

\section{SUMMARY}

Through this article, we try to underline some aspects related to the research undertaken on the book and its different uses. We have centred our attention on the social meanings of possessing a book for private individuals: the book as an instrument of work and/ or study, the book for entertainment, etc. Every single one attests to an attitude of the individual as regards the Written Culture and, above all, the role of the latter in the consolidation of a social status. 